\title{
Às margens da açucaristocracia: segredos internos da Recife da década de 1970 em um conto de Alexandre Furtado
}

Alexander Martins Vianna*

Furtado, Alexandre. Os mortos náo comem açúcar. Rio de Janeiro: Confraria do Vento, 2015. 151p.

Não, não é um romance histórico... O livro Os mortos não comem açúcar também não é coletânea de contos, ou "contos interligados", diferentemente do que sugeriu a Revista Continente ao noticiar o seu lançamento no café-restaurante Roda Cultural de Pernambuco em 21 de maio de 2016. O livro de Alexandre Furtado é um único conto com catorze entradas narrativas, ora assumidas por algum personagem, ora pelo narrador-voz-de-deus, configuradas com vigor de devassa indiciária. A sua estrutura narrativa cria um efeito magnético muito interessante de leitura: os silêncios suspensivos em cada capítulo são rachaduras que formam metonímias indiciárias de sentido que estão longe de serem banais e previsíveis. Cada capítulo envolve a perspectiva inevitavelmente parcial de cada modelo de narrador que nele predomina. Assim são revelados, aos poucos, os horrores formativos das existências presentes e passadas dos personagens que vivem à margem da açuca- ristocracia de Recife. Por conta de sua estrutura narrativa, parece interessante abordar o livro de Alexandre Furtado a partir de alguns caracteres que engenhosamente ganham carnadura em cada capítulo.

As tramas de vidas narradas no conto transcorrem na Recife de começos da década de 1970, no polo social da classe média alta, urbana e de serviços, que ainda tenta imitar, no traquejo social e na moralidade, as formas de distinção referidas à grandeza passada da açucaristocracia de Pernambuco. Há pequenos momentos de recuo para situar a trajetória de alguns personagens, mas o polo da trama gira em torno da expectativa do casamento de Laura e Fabio. Laura é filha de Silvina, que é esposa do comunista domesticado Marco Aurélio. Silvina e Marco Aurélio são pais de Pedro, que é irmão de Laura e jovem cobiçado por Albertina - a esguia, blasé, afrancesada, cu-sujo e aparentemente inacessível (fruta podre) jovem da açucaristocracia decadente de Pernambuco. Albertina contrasta fisicamente e sexualmente com o seu inseguro, gordinho, delicado, ejaculador precoce e pouco atrativo irmão Gabriel.

No presente e no passado de Laura e Sil- 
vina, há um mistério revelado aos poucos, por pequenas fendas narrativas, até o grande confronto de suas semelhanças, durante o casamento, no capítulo "Aos céus um pedido" (p. 139-151). Contudo, nos engenhosos mecanismos narrativos de Furtado, as vidas que se cruzam com a ascensão social de Silvina são reveladas pelas margens sociais, as quais abrem a possibilidade de o conto falar também a partir dessas vidas à margem ou melhor, margens, sem as quais não haveria os centros dos pequenos horrores formativos de suas existências. Ao criar fendas extraordinárias devassantes da complexidade formativa das vidas dos personagens, tal estratégia de narrar a partir das margens é um dos grandes méritos de figuração de caracteres no conto de Furtado.

A aderência narrativa às margens é uma escolha de composição que não cria um efeito de maniqueísmo vítima-algoz; pelo contrário, revela gradativamente a complexidade do horror formativo das vidas que ainda giram paradigmaticamente em torno de saudosas referências à grandeza (violenta) da açucaristocracia. Não há um personagem que não espelhe, de seu lugar, a violência sutil que o forma: a desigualdade social, racial e de gênero; a caridade e a relação funcional-vingativa entre desiguais (sociais, raciais e de gêneros) no espaço doméstico patriarcal; o amor que pode se revelar e se fazer nas brechas dessas desigualdades (ou igualdades) sociais, raciais e de gêneros. $\mathrm{O}$ fato é que a barca do patriarcado recifense da década de 1970 faz água por todos os lados. São as fendas extraordinárias abertas pela lâmina narrativa de Furtado.
Há importância especial no fato de as narrativas parcialmente se centrarem nos jovens amigos de começos da década de 1970: por meio deles, os pais são revelados, mesmo aqueles que não têm existência enunciada em corpo narrativo. Embora preocupados em manter alguma aparência (particularmente no caso das mulheres de classe média), os jovens já têm o aval tácito dos pais para namorarem sem vigília acirrada: vão ao cinema, namoram sozinhos em casa, avançam o sinal, engravidam, abortam ou fazem casamento corretivo-ocultativo de gravidez não planejada. Portanto, mesclam o velho com novos padróes de pudor e hipocrisia social. Contudo, o que é brechtianamente assombroso na caracterização dos personagens de Furtado são os pais desses jovens ou, mais especificamente, as mães: donas de seu desejo em estratégica negociação corpo-mente nas margens da aparência de submissão aos códigos do patriarcado recifense.

Assim, os seus paradoxos são revelados: não há descendência ou linhagem plenamente segura no casamento, porque o próprio segredo no modo de viver a liberdade sexual cria válvulas de escapes que provocam múltiplas porosidades sociais, raciais e de gênero. Como a liberdade sexual ocorre enquanto segredo, não há liberação sexual em relação às regras de boa aparência social configuradas por binarismos raciais e de gênero. Assim, as mães socialmente brancas da classe média são donas de seu prazer por meio de adultério (bissexual) bem discreto; os pais e filhos têm os puteiros ou as áreas de serviço ao preço das filhas mal empregadas e mal nutridas dos desvalidos; as filhas social- 
mente brancas da classe média têm os seus namorados ou noivos para desafogo (mas também outros paralelos), com a anuência tácita de suas mães.

Dentre as mães que revelam as fendas no patriarcado, Silvina é um exemplo marcante no conto de Furtado: retirante de pele clara, isso a levou para lugares que foram negados às outras meninas da Casa 10. Ao cair nas graças do manipulador prof. Olavo, Silvina terminou o seu romance com a amiga Juliana, a qual se tornara dona e gestora do principal bordel de Recife. Depois disso, houve uma total reinvenção social de Silvina, à custa da educação e do suicídio de sua bem letrada mãe adotiva: Lúcia, que foi casada em segunda núpcia com Olavo. Este trouxera Silvina da Casa 10 para ser companhia filial para a infértil Lúcia; mas, em surdina, continuaram sendo amantes. Quando descobertos, isso provocou a depressão e o suicídio de Lúcia, expresso no surpreendente engenho narrativo do capítulo “Tristam Shandy c'est moi ou beijo de língua” (p. 90-100), no qual é a própria suicida que se narra enquanto a vida deixa o seu corpo.

Olavo era o pai biológico de Laura. Pouco antes de Laura nascer, Silvina casara com seu marido-tampão Marco Aurélio, um comunista doméstico que começou a envolver-se sexualmente com Laura desde o começo de sua puberdade. Silvina só soube disso no dia do casamento de Laura, quando ambas confrontaram seus segredos e suas semelhanças. Portanto, em certa medida, a falta de liberação sexual e a desigualdade de gênero em desfavor das mulheres da geração de Silvina criavam uma codificação específica de sujei- to e liberdade sexual (escondida) configurada nos termos dos segredos do patriarcado. Esta é outra fenda extraordinária de Furtado, cuja reflexão se intensifica na narrativa do capítulo "Deus proteja os sem-vergonha" (p. 68-79), no qual o narrador-voz-de-deus devassa, pelas frestas, a consciência manipuladora das boas aparências da bem reputada Sueli, esposa do major Paulo e mãe de Ângela e Febo.

A hipocrisia da boa aparência é sustentada por várias válvulas perversas de escape. Perante a preocupada Silvina, Sueli figura como uma verdadeira tratadista sobre como ser dona de seu prazer por meio do adultério com o menor dano colateral possível para a família. Sueli e Silvina também tiveram um caso amoroso lésbico já sendo senhoras casadas, mas deixaram isso no passado... O que mobilizou a inesperada visita de Silvina foi a sua gravidez do médico Laércio. Ela queria abortar. Sueli também era amante de Laércio. Isso é engenhosamente revelado para o leitor por meio de seu diálogo à parte com a empregada Inácia. Sueli tinha gozo perverso por esta situação (p. 77). Portanto, no silêncio das frestas dessas senhoras com "S", havia muita inveja e concorrência.

Náo por acaso, Furtado reforça os paralelos entre Sueli e Silvina pelo fato de ambas terem casais de filho regulando na mesma idade - e, por que não dizer, ambas tinham maridos-tampão, mesmo que adversos: milico e comunista, respectivamente. Silvina nunca soube que Sueli tinha também caso com Laércio. Mas, nessa visita a Sueli, Silvina ficou surpreendida com a sua desenvolta postura consoladora ao usar exemplos domésticos. Silvina se sentia inferior a Sueli 
por seu passado de retirante que trabalhou como faxineira na Casa 10 , mas a verdadeira aula de Sueli sobre como ser dona de seu prazer por meio do adultério - sem culpa e dano à família — deixou empatado o jogo social-moral entre ambas. Mais uma fenda extraordinária criada pela engenhosa lâmina narrativa de Furtado...

No seu conjunto, o livro de Furtado demonstra grande aproveitamento narrativo-borgiano dos detalhes significativos de longo alcance. Por isso, quando terminamos de lê-lo, ficamos com vontade de experimentar o livro de um lugar de onisciência que não é possível até a última página. O livro não se entrega fácil, não se reduz a clichês ou estereótipos de caracteres. Cada metonímia de silêncio é um convite a novos indiciamentos. Quando voltamos ao começo, detalhes suspensivos se amplificam em nosso cinismo cúmplice: somos o deus-fora-da-máquina-do-conto; somos o lugar de quem o escreve; saboreamos o seu processo de criação; reconhecemos a precisão narrativa dos seus recortes de silêncios; surpreendemo-nos com a forma como traz a língua-viva autônoma de cada personagem. Na máquina do conto de Furtado, há o domínio completo da arte que abre brechas na cegueira dos costumes, margina o silêncio grávido de horrores sociais e o ambienta num plano de critérios que visam a provocar deslocamentos críticos em relação a esquemas estereotípicos de caracterização na própria arte narrativa dos contos pós-Kafka, ou dos romances regionais pós-Jorge Amado.

O bom manejo da língua viva - talhada com limpidez de acordo com o lugar do narrador e/ou dos personagens - explora alguns motivos recorrentes: a bissexualidade (masculina e feminina); o adultério; a liberdade sexual feminina sem liberação sexual; a decadência física-moral-social da açucaristocracia; a hipocrisia das aparências de respeitabilidade social configurada em termos de binarismo racial e de gênero; a dignificação narrativa de marginais, como Juliana e Inácia, mas também reveladora do horror formativo de seus corpos e subjetividades; a evidente simpatia narrativa por Antônio em contraponto ao que representa Albertina. Há também o cuidado de criar efeito trágico surpreendente ao situar Silvina como mote dos suicídios de Lúcia e Juliana, ou seja, as duas mulheres que a amaram, a resgataram e a prepararam, ao seu modo, para a ascensão social: da retirante estuprada à senhora casada e educada.

Antônio é outra fenda extraordinária da açucaristocracia decadente de Recife que é revelada aos poucos: produto da caridade funcional do matriarcado sobreviventista das áreas de serviços das “casas grandes”, Antônio cresceu em proximidade afetiva, social e cultural aos filhos dos patrôes de sua mãe e avó, tendo acesso à mesma escolaridade. Antônio é apaixonado por Cosme e fascinado por Albertina. Diferentemente de Sueli e Silvina, que são "S's" paralelos, Antônio e Albertina são "A's" social e racialmente adversos. Antônio é invisível para Albertina, que tem interesse sexual-predatório em Pedro, irmão mais novo de Laura. Os amigos ricos de Antônio periodicamente o lembravam que Albertina não era "para seu bico" de jovem engenheiro de origem negra e pobre.

Antônio e Cosme se percebem bis- 
sexuais... No capítulo dessa revelação, é Cosme que assume a narrativa. E vemos o seu fluxo de consciência migrando do particular ao cósmico. Trata-se de um momento especial no qual a narrativa concilia o meditativo-cósmico à árida delicadeza de "um montão de [grandes sertôes] veredas" (p. 35) pelas quais caminhamos. Ambos não têm categorias para entenderem como sentem o que sentem "assim, quando menos se espera” (p. 25-35), mas o beijo impresso na pele encontra a recepção da carícia que se posterga, como uma sutil promessa que, no futuro, também poderia esconder-se num casamento-tampão... Tal afeição delicada é o oposto narrativo-tipológico da "macheza cênica” de Tales (namorado de Ângela, filha de Sueli) para os seus amigos na Casa 10: Ele acha que é um segredo vergonhoso-perigoso o seu gosto especial por fio-terra (p. 40). Em si mesma uma marginação do patriarcado, a Casa 10 tem em tais segredos os seus mais importantes recursos imateriais que possibilitam a sua sobrevivência social e econômica. O segredo é a alma desse negócio porque a vergonha machista ainda movimenta o corpo pútrido do patriarcado.

Dentre as várias operaçóes pelas margens no conto de Furtado, destaco, por fim, o capítulo "Uma história assim é outra" (p. 123-131), no qual a voz narrativa é assumida por Inácia, cuja língua viva aparece com a autenticidade que passa longe da estereotipia. No estilo de Inácia, nota-se a sua revelação corpo-mente sobreviventista: como sente, pensa e revela o seu passado e a si mesma no presente; como lida com seus desejos; por que casar não é a melhor opção para ela; a violência estrutural que sofre sem percebê- -la; o amor platônico que a desloca para fora dos hábitos violentos do patriarcado; as suas pequenas vinganças contra a patroa (Sueli), o patrão (major Paulo) e seus filhos (Ângela e Febo); os sexos ocasionais com Paulo e (e) Febo; os sexos ocasionais de fora da casa (mas dentro da casa) dos patróes... Tudo revelado numa voz narrativa leskoviana na qual autenticamente ouvimos Inácia em sua lógica formativa discorrendo-se para o leitor sem residuais interferências explicativas do autor.

Com Inácia, temos o nadir narrativo de Furtado encarnando perfeitamente o sentido crítico da "guerra de compreensão" dos modelos de narradores propostos pela poética contemporânea de Alberto Lins Caldas. Inácia transcorre em total autonomia em relação a Furtado - e, em certa medida, em relação aos homens em sua vida sobreviventista no patriarcado. Na máquina narrativa do conto de Furtado, Inácia se entrega ao leitor como se entrega aos seus homens: pelas frestas, pelas margens... Com tais operações engenhosas, Furtado agarra nos corpos narrativos do seu conto os vários nacos dos horrores formativos corpo-mentes dos personagens socialmente bem assentados, mas que vivem à margem da açucaristocracia decadente e refletem os seus rizomais sintomas. Aliás, como afirma Inácia, "uma história assim é outra" (p. 131): aquela dos muitos desconcertantes enigmas e fragmentos amargos de horrores da decadente açucaristocracia recifense da década de $1970 . .$.

Dizer mais é entregar cedo o doce que só os vivos comem... Então, recomendo: embrenhem-se no conto Os mortos não comem açúcar! Aqui deixei apenas algumas tramas furtadas de Alexandre. 